\title{
Treating seizures and epilepsy with anticoagulants?
}

\author{
Nicola Maggio ${ }^{1,2}$ *, Ilan Blatt ${ }^{2,3}$, Andreas Vlachos ${ }^{4}$, David Tanne ${ }^{2,3}$, Joab Chapman ${ }^{2,3}$ and Menahem Segal ${ }^{5}$ \\ ${ }^{1}$ Talpiot Medical Leadership Program, The Chaim Sheba Medical Center, Tel HaShomer, Israel \\ 2 Department of Neurology, The J. Sagol Neuroscience Center, The Chaim Sheba Medical Center, Tel HaShomer, Israel \\ ${ }^{3}$ Department of Neurology, Sackler Faculty of Medicine, Tel Aviv University, Tel Aviv, Israel \\ ${ }^{4}$ Institute of Clinical Neuroanatomy, Neuroscience Center, Goethe-University Frankfurt, Frankfurt/Main, Germany \\ ${ }^{5}$ Department of Neurobiology, The Weizmann Institute of Science, Rehovot, Israel
}

\section{Edited by:}

Enrico Cherubini, International School for Advanced Studies, Italy

\section{Reviewed by:}

Andrea Nistri, Scuola Internazionale Superiore di Studi Avanzati, Italy Giuliano Avanzini, Fondazione IRCCS Istituto Neurologico Carlo Besta, Italy

\section{*Correspondence:}

Nicola Maggio, Department of Neurology, The J. Sagol Neuroscience Center, The Chaim Sheba Medical Center, 52621 Tel HaShomer, Israel. e-mail: nicola.maggio@sheba.health. gov.il
Thrombin is a serine protease playing an essential role in the blood coagulation cascade. Recent work, however, has identified a novel role for thrombin-mediated signaling pathways in the central nervous system. Binding of thrombin to protease-activated receptors (PARs) in the brain appears to have multiple actions affecting both health and disease. Specifically, thrombin has been shown to lead to the onset of seizures via PAR-1 activation. In this perspective article, we review the putative mechanisms by which thrombin causes seizures and epilepsy. We propose a potential role of PAR-1 antagonists and novel thrombin inhibitors as new, possible antiepileptic drugs.

\section{Keywords: thrombin, PAR-1, seizures, blood-brain barrier, novel anticoagulants}

\section{THROMBIN SIGNALING IN THE BRAIN}

Thrombin is a serine protease, which plays an essential role in the blood coagulation cascade (Siller-Matula et al., 2011). Upon its formation following the enzymatic cleavage of prothrombin by activated Factor $\mathrm{X}$, thrombin regulates a cascade of proteolytic events ultimately leading to the formation of blood clots (Lippi et al., 2012). Lately, however, novel signaling cascades mediated by thrombin have been discovered (Siller-Matula et al., 2011). Specifically, through the activation of the protease-activated receptors (PARs), thrombin seems to directly affect the activity of multiple cell types and regulate a variety of biological functions, such as inflammation, leukocyte migration, cellular proliferation, vascular permeability and tone, edema formation, and other processes related to tissue repair (Coughlin, 2000, 2001; Sambrano etal., 2001; Chen and Dorling, 2009; Schuepbach etal., 2009; Spiel et al., 2011).

Protease-activated receptors belong to a unique family of $\mathrm{G}$ protein-coupled receptors (Luo et al., 2007). Their activation is initiated by an irreversible site-specific proteolytic cleavage in the $\mathrm{N}$-terminal extracellular region. The uncovered $\mathrm{N}$-terminal region then acts as a tethered ligand which activates the receptor (Gingrich and Traynelis, 2000). PARs are expressed in the brain and while PAR-2 represents a class of trypsin/tryptase-activated receptors, PAR-1, PAR-3, and PAR- 4 are most effectively activated by thrombin (Gingrich and Traynelis, 2000). In the brain, PAR-1 has been detected in both neurons and astrocytes, with the latter demonstrating stronger immunoreactivity in human brain tissue (Junge et al., 2004). High levels of PAR-1 are detected in the hippocampus, cortex, and striatum of humans (Junge et al., 2004). While the molecular pathways activated by PAR-1 in neurons are yet under investigation, in the brain PAR-1 activation has been shown to modulate synaptic transmission and plasticity through the enhancement of $N$-methyl-D-aspartate (NMDA) receptor
(NMDAR) currents (Gingrich et al., 2000; Lee et al., 2007; Maggio et al., 2008). In addition, PAR-1 knockout animals present profound deficits in hippocampus-dependent learning and memory processes (Almonte et al., 2007, 2013). Altogether, it seems that PAR-1 plays a critical role in memory formation and synaptic plasticity.

Interestingly, a variety of pathological conditions have been associated with changes in the expression of PAR-1 in the brain. In Parkinson's disease, a significant increase in the number of astrocytes expressing PAR-1 has been reported in the substantia nigra pars compacta (Ishida et al., 2006). In addition, upregulation of PAR-1 in astrocytes has been observed in HIV encephalitis, (Boven et al., 2003) indicating that this receptor might be implicated in the pathogenesis of neuroinflammation. This idea is supported by the evidence of elevated levels of thrombin in an experimental model of multiple sclerosis (Beilin et al., 2005) as well as in other inflammatory brain diseases (Chapman, 2006). Stimulation of PAR-1 by thrombin causes proliferation of glia and potentially produces reactive gliosis, infiltration of inflammatory cells, and angiogenesis (Striggow et al., 2001). Finally, expression of PAR-1 is increased in experimental models of Alzheimer's disease (Pompili et al., 2004) and brain ischemia (Striggow et al., 2001).

\section{THROMBIN CAUSES SEIZURES AND EPILEPSY THROUGH PAR-1 ACTIVATION}

Serine proteases are normally expressed in the brain at very low level (Luo et al., 2007). Nevertheless, their concentration can increase abnormally following the breakdown of the bloodbrain barrier (BBB). Under this scenario, a large, non-selective increase in the permeability of brain capillaries and tight junctions takes place, allowing the entry of high molecular weight proteins (Ballabh etal., 2004) and blood components into the cerebral tissue. This event can occur under several neurological 
conditions (Ballabh et al., 2004; Tomkins et al., 2007), particularly after hemorrhagic/ischemic stroke (Hjort et al., 2008; Bang et al., 2009) or traumatic brain injury (TBI; Barzo et al., 1997; Tomkins et al., 2008). Although there is a paucity of information concerning the amount of thrombin crossing the $\mathrm{BBB}$, it has been demonstrated that thrombin levels increase more than 200 -fold (from $100 \mathrm{pM}$ to $25 \mathrm{nM}$ ) in the cerebrospinal fluid of patients with subarachnoid cerebral hemorrhage (Suzuki et al., 1992). In addition, when the bleeding occurs directly within the brain tissue, active thrombin and other proteases can freely diffuse into the brain parenchyma until clotting closes off the injured vessels. In this respect, our preliminary data suggest that under experimental conditions, depletion of thrombin from the clot appears to be continuous, with the concentration of thrombin in cerebrospinal fluid increasing several-folds over a 24 -h time window.

A direct consequence of the contact of thrombin with the brain tissue is the onset of seizures. Lee et al. (1997) reported that intracerebral injections of thrombin resulted in focal motor seizures. Interestingly, thrombin injected together with its inhibitor alpha(2-naphthylsulfonyl-glycyl)-4-amidinophenylalanine piperidide (alpha-NAPAP) did not cause any sign of either clinical or electrographic seizures (Lee et al., 1997). Similarly, mice engineered to lack protein Nexin-1, an endogenous thrombin inhibitor, have an increased susceptibility to kainic acid-induced seizures (Luthi et al., 1997). Our own work has demonstrated that thrombininduced seizures are mediated by activation of PAR-1 (Maggio et al., 2008). In hippocampal slices, thrombin at a concentration of $5 \mathrm{nM}(1 \mathrm{U} / \mathrm{ml})$ increases spontaneous firing of CA3 pyramidal cells (Maggio et al., 2008). In order to examine whether thrombin facilitates the onset of epileptic discharges in conditions mimicking a BBB breakdown in the slice (Chen and Swanson, 2003; Beart and O'Shea, 2007), we exposed neurons to thrombin in presence of elevated $\left[\mathrm{K}^{+}\right]_{\mathrm{o}}$ or low levels of glutamate. In normal slices, addition of $4 \mathrm{mM} \mathrm{K}^{+}$did not produce any noticeable spontaneous seizures, which were clearly seen when $\left[\mathrm{K}^{+}\right]$were raised by $15 \mathrm{mM}$. Similarly, $500 \mu \mathrm{M}$ but not $100 \mu \mathrm{M}$ glutamate produced spontaneous seizure-like activity in the slice. Strikingly, thrombin facilitated the response to the lower concentration of $\mathrm{K}^{+}(4 \mathrm{mM})$ and glutamate $(100 \mu \mathrm{M})$ to produce seizure-like activity. This activity was mediated by PAR-1 activation, since it was mimicked by a peptide agonist of the receptor and blocked by its antagonist SCH79797. Interestingly, the facilitatory action of thrombin on the production of seizure-like activity did not depend on NMDARs as it was not affected by the selective NMDAR-inhibitors ifenprodil or by $2 \mathrm{R}$-amino-5-phosphonovaleric acid (APV). Recently, Isaeva et al. (2012) exposed hippocampal slices from immature rats $(\mathrm{P} 6$ to $\mathrm{P} 15)$ to large concentrations of thrombin $(10 \mathrm{U} / \mathrm{ml})$ to find that thrombin depolarized membrane potential of neurons and produced a hyperpolarizing shift of tetrodotoxin-sensitive $I_{\text {Nap }}$ through a PAR-1-mediated mechanism (Isaeva et al., 2012). In addition, we have reported that thrombin affects synaptic transmission in hippocampal CA3 neurons by enhancing both frequency and amplitude of mEPSCs while reducing frequency and amplitude of mIPSCs (Maggio et al., 2012). Taken together, these studies clearly indicate a proepileptic effect of thrombin which upon PAR-1 activation induces membrane and synaptic changes

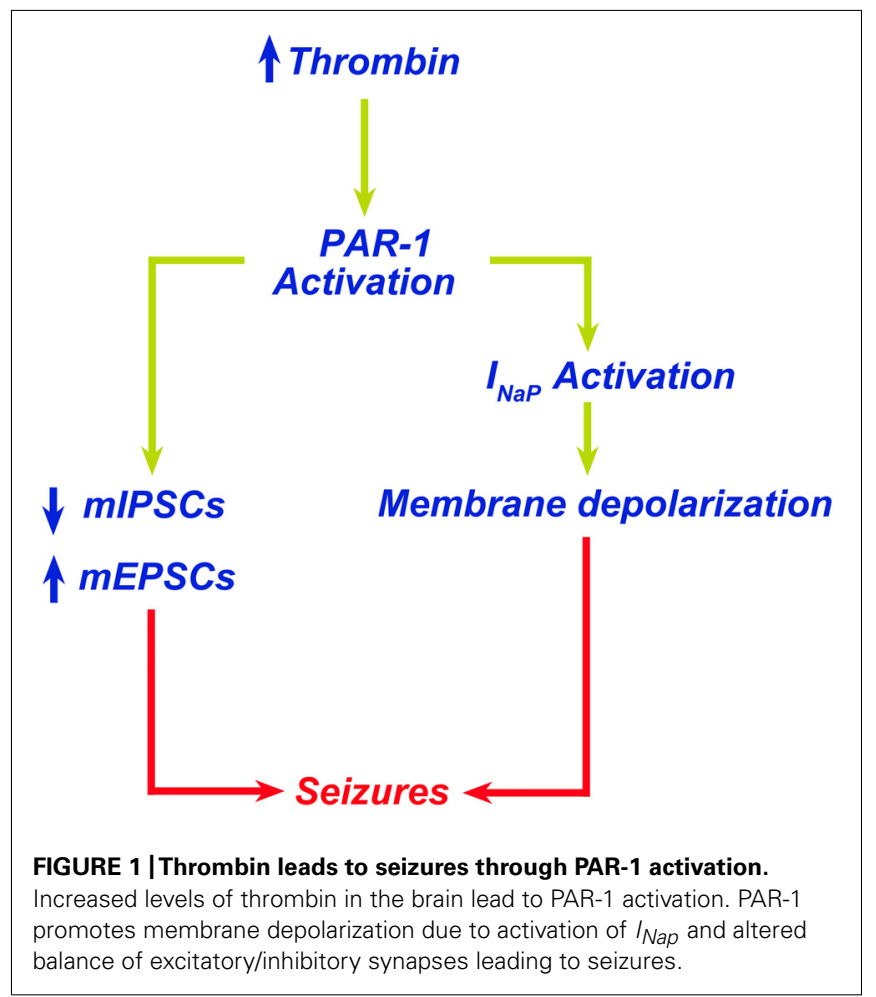

leading to seizures (Figure 1). Less clear, however, is whether the thrombin-induced increase in neuronal activity could lead to epilepsy later on. Indeed, it has been demonstrated that high concentrations of thrombin, usually reached in pathological settings following thrombin extravasation into the brain, may induce apoptosis (Lee da et al., 2006; Wang et al., 2006; Xi et al., 2006; Luo et al., 2007). Accordingly, thrombin-induced neuronal cell loss could lead to circuit reorganization and onset of epilepsy. While circuit reorganization following injury is a well known cause of hyper excitability (Heinemann et al., 2002; Heinemann, 2004), no information is currently available on the possible role of thrombin and PAR- 1 activation in this situation.

\section{PAR-1 ANTAGONISTS AND THROMBIN INHIBITORS AS NEW ANTIEPILEPTIC DRUGS?}

Seizures and epilepsy are commonly observed in conjunction with stroke, TBI, and central nervous system infections, all conditions known to result in compromised BBB function (Tomkins et al., 2001; Ballabh et al., 2004). Regional patterns of BBB breakdown have been described during epileptiform seizures induced in animal models by various convulsive agents (Nitsch and Klatzo, 1983). Following BBB breakdown, seizures result from the exposure of the brain to serum components such as thrombin due to the increased permeability of the BBB (Kelly, 2008). In fact, even in the absence of hemorrhage, BBB breakdown may activate the coagulation cascade leading to intracerebral generation of thrombin (Stein et al., 2002; Chodobski et al., 2011; Pisapia et al., 2012). In this setting an enduring $\mathrm{BBB}$ breakdown due to uncontrolled seizures may lead to a continuous leak of thrombin into the brain, which in turn sustains the epileptic process (Figure 2). 


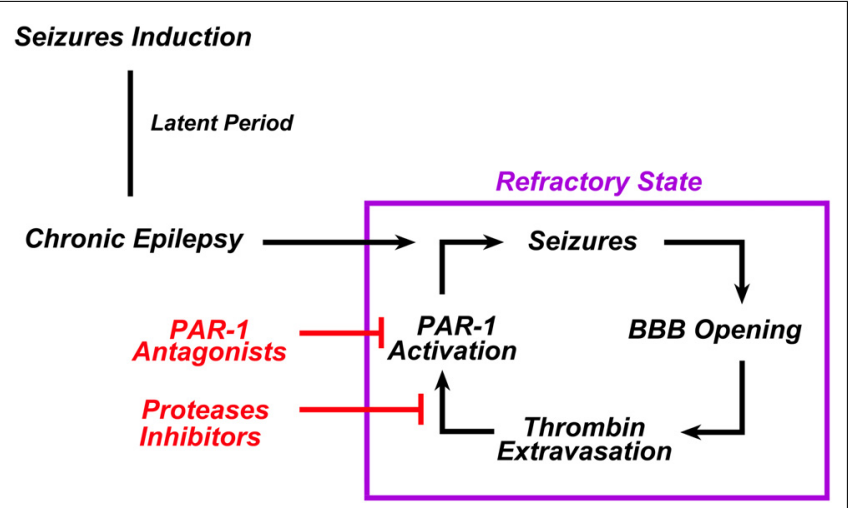

FIGURE 2 | In chronic epilepsy, thrombin constantly sustains the epileptic process. In chronic epilepsy, recurrent seizures lead to the breakdown of BBB. Extravasation of thrombin from the blood into the brain tissue activates PAR-1 in the brain. PAR-1 activation sustains or even enhances the epileptogenic processes responsible for the refractoriness of such syndrome. The use of either PAR-1 antagonists and/or serine proteases inhibitors could break this vicious cycle and prevent the occurrence of refractoriness.

If thrombin indeed is the major reason for seizures in this condition, it is tempting to speculate that PAR-1 antagonists and/or thrombin inhibitors could act as potential antiepileptic drugs. PAR-1 antagonists are a class of drugs currently tested in the context of cardiovascular diseases (Ahn et al., 2003; Landis, 2007; Lee and Hamilton, 2012). They are non-peptide small molecular compounds which differ in their effectiveness to inhibit PAR-1 (Ahn et al., 2003). They have both anticoagulant (Wielders et al., 2007) and antiaggregant (Lee and Hamilton, 2012) properties. However, unlike a direct thrombin inhibitor, they are thought to have minimal bleeding side-effects due to the inability of blocking the enzymatic action of thrombin in the coagulation cascade. We (Maggio et al., 2008, 2012) and others (Isaeva et al., 2012) have indeed shown that PAR-1 antagonists block the proepileptogenic effects of thrombin in vitro, however, no data currently exist on the role of PAR-1 antagonists as antiepileptic drugs in animal models of epilepsy following BBB breakdown. Furthermore, it is not known whether thrombin and PAR-1 levels are increased in the brains of experimental animals undergoing chronic epilepsy. In this context, our preliminary data based on $\mathrm{Li}^{2+}$ - pilocarpine treated animals do show that this might indeed be the case. Interpretation of clinical data might provide important insights as well. Cardiac surgery has been associated with a high rate of seizures in the post-operative settings (Goldstone et al., 2011a,b; Hervey-Jumper et al., 2011). Thus, are patients treated with PAR-1 antagonists as prevention to reduce the prothrombotic risk occurring in cardiothoracic surgery (Landis, 2007) going to show less seizures in their post-operative outcomes?

\section{REFERENCES}

Ahn, H. S., Chackalamannil, S., Boykow, G., Graziano, M. P., and Foster, C. (2003). Development of proteinaseactivated receptor 1 antagonists as therapeutic agents for thrombosis, restenosis and inflammatory diseases. Curr. Pharm. Des. 9, 23492365.

Almonte, A. G., Hamill, C. E., Chhatwal, J. P., Wingo, T. S., Barber, J. A., Lyuboslavsky, P. N., etal. (2007). Learning and memory deficits in mice lacking

Thrombin is the target of a newly developed class of anticoagulants proposed as alternatives to vitamin K-dependent anticoagulants for the prevention of stroke and systemic embolism in patients with atrial fibrillation (Zikria and Ansell, 2009; Dentali et al., 2012; Haft, 2012). Do these molecules have an antiepileptic activity as well? In this respect, the novel direct thrombin inhibitor, dabigatran, which blocks the proteolytic activity of thrombin, might mimic the antiepileptic effect of alpha-NAPAP by preventing the thrombin-dependent activation of PAR-1. A similar result, using a different mechanism may be achieved by the novel direct Factor X inhibitors, apixaban and rivaroxaban, which halt Factor $\mathrm{X}$ from converting prothrombin to thrombin. Currently, no clinical and experimental data are available to analyze whether these molecules might have a role in the prevention of seizures and epilepsy upon brain exposure to high intracerebral concentrations of thrombin. Indeed, it might be interesting to evaluate whether patients taking direct thrombin inhibitors for secondary stroke prevention are less prone to the development of seizures, a known complication of stroke. This being the case, our approach justifies the use of these drugs as more advantageous compared to the old vitamin K-dependent anticoagulants. A possible disadvantage for the use of these drugs in epileptic patients might be related to the increased risk of bleeding in people experiencing recurrent falls due to seizures. This is certainly possible, however, studies are needed to evaluate whether the dosage required for full anticoagulation are similar to the ones needed to reach an antiepileptic effect: thrombin concentrations are far higher in the serum (Siller-Matula et al., 2011) than in the brain following BBB breakdown (Striggow et al., 2000). The use of these drugs might as well be proposed in patients which may develop epilepsy following brain hemorrhage. This should however be very carefully considered by taking into account the type and modalities of the bleeding as well as possible continuation of anticoagulation in a population of patients at risk of recurrence.

In conclusions, work from recent years has disclosed a novel and clinically highly relevant role for thrombin in the pathogenesis of hyperexcitability in neuronal networks and the development of seizures and epilepsy. However, more data are needed to evaluate the precise role of thrombin in epilepsy. The identification of the thrombin-PAR-1 pathway playing a fundamental role in the pathophysiology of epilepsy may lead to the development of new therapeutic strategies and provide a rationale for testing PAR1 antagonists and/or thrombin inhibitors in animal models of epilepsy.

\section{ACKNOWLEDGMENT}

This research was supported by a Grant from the GIF, the GermanIsraeli Foundation for Scientific Research and Development to Nicola Maggio.

protease activated receptor-1. Neurobiol. Learn. Mem. 88, 295-304.

Almonte, A. G., Qadri, L. H., Sultan, F. A., Watson, J. A., Mount, D. J., Rumbaugh, G., et al. (2013). Protease-activated receptor-1 modulates hippocampal memory formation and synaptic plasticity. J. Neurochem. 124, 109-122.

Ballabh, P., Braun, A., and Nedergaard, M. (2004). The blood-brain barrier: an overview: structure, regulation, 
and clinical implications. Neurobiol. Dis. 16, 1-13.

Bang, O. Y., Saver, J. L., Alger, J. R., Shah, S. H., Buck, B. H., Starkman, S., et al. (2009). Patterns and predictors of blood-brain barrier permeability derangements in acute ischemic stroke. Stroke 40, 454-461.

Barzo, P., Marmarou, A., Fatouros, P., Hayasaki, K., and Corwin, F. (1997). Contribution of vasogenic and cellular edema to traumatic brain swelling measured by diffusionweighted imaging. J. Neurosurg. 87, 900-907.

Beart, P. M., and O'Shea, R. D. (2007). Transporters for L-glutamate: an update on their molecular pharmacology and pathological involvement. Br. J. Pharmacol. 150, 5-17.

Beilin, O., Karussis, D. M., Korczyn, A. D., Gurwitz, D., Aronovich, R., Hantai, D., et al. (2005). Increased thrombin inhibition in experimental autoimmune encephalomyelitis. $J$. Neurosci. Res. 79, 351-359.

Boven, L. A., Vergnolle, N., Henry, S. D., Silva, C., Imai, Y., Holden, J., et al. (2003). Up-regulation of proteinaseactivated receptor 1 expression in astrocytes during HIV encephalitis. J. Immunol. 170, 2638-2646.

Chapman, J. (2006). Thrombin in inflammatory brain diseases. Autoimmun. Rev. 5, 528-531.

Chen, D., and Dorling, A. (2009). Critical roles for thrombin in acute and chronic inflammation. J. Thromb. Haemost. 7(Suppl. 1), 122-126.

Chen, Y., and Swanson, R. A. (2003). Astrocytes and brain injury. J. Cereb. Blood Flow Metab. 23, 137-149.

Chodobski, A., Zink, B. J., and Szmydynger-Chodobska, J. (2011). Blood-brain barrier pathophysiology in traumatic brain injury. Transl. Stroke Res. 2, 492-516.

Coughlin, S. R. (2000). Thrombin signalling and protease-activated receptors. Nature 407, 258-264.

Coughlin, S. R. (2001). Proteaseactivated receptors in vascular biology. Thromb. Haemost. 86, 298-307.

Dentali, F., Riva, N., Crowther, M., Turpie, A. G., Lip, G. Y., and Ageno, W. (2012). Efficacy and safety of the novel oral anticoagulants in atrial fibrillation: a systematic review and meta-analysis of the literature. Circulation 126, 2381-2391.

Gingrich, M. B., Junge, C. E., Lyuboslavsky, P., and Traynelis, S. F. (2000). Potentiation of NMDA receptor function by the serine protease thrombin. J. Neurosci. 20, 45824595.

Gingrich, M. B., and Traynelis, S. F. (2000). Serine proteases and brain damage - is there a link? Trends Neurosci. 23, 399-407.

Goldstone, A. B., Bronster, D. J. Anyanwu, A. C., Goldstein, M. A., Filsoufi, F., Adams, D. H., et al. (2011a). Predictors and outcomes of seizures after cardiac surgery: a multivariable analysis of 2,578 patients. Ann. Thorac. Surg. 91, 514-518.

Goldstone, A. B., Bronster, D. J., and Chikwe, J. (2011b). Seizures after adult cardiac surgery. J. Cardiothorac. Vasc. Anesth. 25, e25-e26.

Haft, J. I. (2012). Stroke prevention in atrial fibrillation: impact of novel oral anticoagulants. Clin. Appl. Thromb. Hemost. doi: 10.1177/1076029612458148 [Epub ahead of print].

Heinemann, U. (2004). Basic mechanisms of partial epilepsies. Curr. Opin. Neurol. 17, 155-159.

Heinemann, U., Buchheim, K., Gabriel, S., Kann, O., Kovacs, R., and Schuchmann, S. (2002). Cell death and metabolic activity during epileptiform discharges and status epilepticus in the hippocampus. Prog. Brain Res. 135, 197-210.

Hervey-Jumper, S. L., Annich, G. M., Yancon, A. R., Garton, H. J., Muraszko, K. M., and Maher, C. O. (2011). Neurological complications of extracorporeal membrane oxygenation in children. J. Neurosurg. Pediatr. 7, 338-344.

Hjort, N., Wu, O., Ashkanian, M. Solling, C., Mouridsen, K., Christensen, S., et al. (2008). MRI detection of early blood-brain barrier disruption: parenchymal enhancement predicts focal hemorrhagic transformation after thrombolysis. Stroke 39, 1025-1028.

Isaeva, E., Hernan, A., Isaev, D., and Holmes, G. L. (2012). Thrombin facilitates seizures through activation of persistent sodium current. Ann. Neurol. 72, 192-198.

Ishida, Y., Nagai, A., Kobayashi, S., and Kim, S. U. (2006). Upregulation of protease-activated receptor1 in astrocytes in Parkinson disease: astrocyte-mediated neuroprotection through increased levels of glutathione peroxidase. J. Neuropathol. Exp. Neurol. 65 66-77.

Junge, C. E., Lee, C. J., Hubbard, K B., Zhang, Z., Olson, J. J., Hepler, J. R., et al. (2004). Proteaseactivated receptor-1 in human brain: localization and functional expression in astrocytes. Exp. Neurol. 188, 94-103.

Kelly, K. M. (2008). Thrombin: is it on a PAR with seizures and epilepsy? Epilepsy Curr. 8, 110-112.
Landis, C. (2007). Why thrombin PAR1 receptors are important to the cardiac surgical patient. J. Extra Corpor Technol. 39, 305-307.

Lee, C. J., Mannaioni, G., Yuan, H. Woo, D. H., Gingrich, M. B., and Traynelis, S. F. (2007). Astrocytic control of synaptic NMDA receptors. J. Physiol. 581, 1057-1081.

Lee, H., and Hamilton, J. R. (2012). Physiology, pharmacology, and therapeutic potential of proteaseactivated receptors in vascular disease. Pharmacol. Ther. 134, 246-259.

Lee, K. R., Drury, I., Vitarbo, E., and Hoff, J. T. (1997). Seizures induced by intracerebral injection of thrombin: a model of intracerebral hemorrhage. J. Neurosurg. 87, 73-78.

Lee da, Y., Park, K. W., and Jin, B. K. (2006). Thrombin induces neurodegeneration and microglial activation in the cortex in vivo and in vitro: proteolytic and non-proteolytic actions. Biochem. Biophys. Res. Commun. 346, 727-738.

Lippi, G., Franchini, M., Montagnana, M., and Favaloro, E. J. (2012). Inherited disorders of blood coagulation. Ann. Med. 44, 405-418.

Luo, W., Wang, Y., and Reiser, G. (2007). Protease-activated receptors in the brain: receptor expression, activation, and functions in neurodegeneration and neuroprotection. Brain Res. Rev. 56, 331-345.

Luthi, A., Van Der Putten, H., Botteri, F. M., Mansuy, I. M., Meins, M. Frey, U., et al. (1997). Endogenous serine protease inhibitor modulates epileptic activity and hippocampal long-term potentiation. J. Neurosci. 17, 4688-4699.

Maggio, N., Cavaliere, C., Papa, M., Blatt, I., Chapman, J., and Segal, M. (2012). Thrombin regulation of synaptic transmission: Implications for seizure onset. Neurobiol. Dis. 50C, 171-178.

Maggio, N., Shavit, E., Chapman, J., and Segal, M. (2008). Thrombin induces long-term potentiation of reactivity to afferent stimulation and facilitates epileptic seizures in rat hippocampal slices: toward understanding the functional consequences of cerebrovascular insults. J. Neurosci. 28, 732-736.

Nitsch, C., and Klatzo, I. (1983). Regional patterns of blood-brain barrier breakdown during epileptiform seizures induced by various convulsive agents. J. Neurol. Sci. 59, 305-322.

Pisapia, J. M., Xu, X., Kelly, J., Yeung, J., Carrion, G., Tong, H., et al. (2012). Microthrombosis after experimental subarachnoid hemorrhage: time course and effect of red blood cell-bound thrombin-activated prourokinase and clazosentan. Exp. Neurol. 233, 357-363.

Pompili, E., Nori, S. L., Geloso, M. C., Guadagni, E., Corvino, V., Michetti, F., et al. (2004). Trimethyltin-induced differential expression of PAR subtypes in reactive astrocytes of the rat hippocampus. Brain Res. Mol. Brain Res. 122, 93-98.

Sambrano, G. R., Weiss, E. J., Zheng, Y. W., Huang, W., and Coughlin, S. R. (2001). Role of thrombin signalling in platelets in haemostasis and thrombosis. Nature 413, 74-78.

Schuepbach, R. A., Feistritzer, C., Fernandez, J. A., Griffin, J. H., and Riewald, M. (2009). Protection of vascular barrier integrity by activated protein $\mathrm{C}$ in murine models depends on protease-activated receptor-1. Thromb. Haemost. 101, 724-733.

Siller-Matula, J. M., Schwameis, M., Blann, A., Mannhalter, C., and Jilma, B. (2011). Thrombin as a multifunctional enzyme. Focus on in vitro and in vivo effects. Thromb. Haemost. 106, 1020-1033.

Spiel, A. O., Bartko, J., Schwameis, M., Firbas, C., Siller-Matula, J., Schuetz, M., et al. (2011). Increased platelet aggregation and in vivo platelet activation after granulocyte colonystimulating factor administration. A randomised controlled trial. Thromb. Haemost. 105, 655-662.

Stein, S. C., Chen, X. H., Sinson, G. P., and Smith, D. H. (2002). Intravascular coagulation: a major secondary insult in nonfatal traumatic brain injury. J. Neurosurg. 97, 1373-1377.

Striggow, F., Riek, M., Breder, J., Henrich-Noack, P., Reymann, K. G., and Reiser, G. (2000). The protease thrombin is an endogenous mediator of hippocampal neuroprotection against ischemia at low concentrations but causes degeneration at high concentrations. Proc. Natl. Acad. Sci. U.S.A. 97, 2264-2269.

Striggow, F., Riek-Burchardt, M., Kiesel, A., Schmidt, W., Henrich-Noack, P., Breder, J., et al. (2001). Four different types of protease-activated receptors are widely expressed in the brain and are up-regulated in hippocampus by severe ischemia. Eur. J. Neurosci. 14, 595-608.

Suzuki, M., Ogawa, A., Sakurai, Y., Nishino, A., Venohara, K., Mizoi, K., etal. (1992). Thrombin activity in cerebrospinal fluid after subarachnoid hemorrhage. Stroke 23, 1181-1182.

Tomkins, O., Friedman, O., Ivens, S., Reiffurth, C., Major, S., Dreier, J. 
P., et al. (2007). Blood-brain barrier disruption results in delayed functional and structural alterations in the rat neocortex. Neurobiol. Dis. 25, 367-377.

Tomkins, O., Kaufer, D., Korn, A., Shelef, I., Golan, H., Reichenthal, E., et al. (2001). Frequent blood-brain barrier disruption in the human cerebral cortex. Cell. Mol. Neurobiol. 21, 675-691.

Tomkins, O., Shelef, I., Kaizerman, I., Eliushin, A., Afawi, Z., Misk, A., et al. (2008). Blood-brain barrier disruption in post-traumatic epilepsy. J. Neurol. Neurosurg. Psychiatry 79, 774-777.
Wang, Y., Luo, W., Stricker, R., and Reiser, G. (2006). Protease-activated receptor-1 protects rat astrocytes from apoptotic cell death via JNKmediated release of the chemokine GRO/CINC-1. J. Neurochem. 98, 1046-1060.

Wielders, S. J., Bennaghmouch, A., Reutelingsperger, C. P., Bevers, E. M., and Lindhout, T. (2007). Anticoagulant and antithrombotic properties of intracellular protease-activated receptor antagonists. J. Thromb. Haemost. 5, 571-576.

Xi, G., Keep, R. F., and Hoff, J. T. (2006). Mechanisms of brain injury after intracerebral haemorrhage. Lancet Neurol. 5, 53-63.

Zikria, J. C., and Ansell, J. (2009). Oral anticoagulation with factor $\mathrm{Xa}$ and thrombin inhibitors: on the threshold of change. Curr. Opin. Hematol. $16,347-356$.

Conflict of Interest Statement: The authors declare that the research was conducted in the absence of any commercial or financial relationships that could be construed as a potential conflict of interest.

Received: 15 January 2013; paper pending published: 05 February 2013; accepted: 13 February 2013; published online: 05 March 2013.

Citation: Maggio N, Blatt I, Vlachos A, Tanne D, Chapman J and Segal M (2013) Treating seizures and epilepsy with anticoagulants? Front. Cell. Neurosci. 7:19. doi: 10.3389/fncel.2013.00019

Copyright (C) 2013 Maggio, Blatt, Vlachos, Tanne, Chapman and Segal. This is an open-access article distributed under the terms of the Creative Commons Attribution License, which permits use, distribution and reproduction in other forums, provided the original authors and source are credited and subject to any copyright notices concerning any thirdparty graphics etc. 